\title{
Performance of 3 Enthesitis Indices in Patients with Peripheral Spondyloarthritis During Treatment with Adalimumab
}

\author{
Philip J. Mease, Filip Van den Bosch, Joachim Sieper, Yinglin Xia, Aileen L. Pangan, \\ and In-Ho Song
}

ABSTRACT. Objective. To evaluate the validity of enthesitis indices in patients with peripheral spondyloarthritis (pSpA).

Methods. The ABILITY-2 study evaluated the efficacy of adalimumab (ADA) versus placebo (PBO) in patients with active pSpA over 12 weeks. Patients received open-label ADA for an additional 144 weeks. Twenty-nine enthesitis sites used in 3 enthesitis scoring systems [Leeds Enthesitis Index (LEI), Spondyloarthritis Research Consortium of Canada (SPARCC) Enthesitis Index, Maastricht Ankylosing Spondylitis Enthesitis Score (MASES)] were assessed; discriminatory capacity and treatment response at Week 12 were calculated by standardized mean difference (SMD) and Guyatt's effect size (ES). Sites showing resolution or new-onset enthesitis from baseline to Week 12 were analyzed.

Results. Overall, 165 patients (ADA, $\mathrm{n}=84 ; \mathrm{PBO}, \mathrm{n}=81$ ) were randomized; $143 \mathrm{had} \geq 1$ enthesitis site at baseline. The LEI (SMD -0.73, ES -1.07) and SPARCC (SMD -0.56, ES -0.99) enthesitis indices showed higher discriminatory ability and treatment response than MASES (SMD -0.32, ES $-0.81)$. At Week 12 , among sites that were positive at baseline, significantly more $(\mathrm{p}<0.05)$ showed resolution among patients treated with ADA versus PBO in the Achilles tendon $(60.4 \%$ and $36.5 \%$, respectively), medial epicondyle $(73.2 \%, 48.7 \%)$, lateral epicondyle $(80.6 \%, 52.8 \%)$, and iliac crest $(73.5 \%, 47.2 \%)$. Among negative sites at baseline, significantly less $(\mathrm{p}<0.05)$ new-onset enthesitis was observed with ADA versus PBO for Achilles tendon (3.6\% and 10.9\%, respectively), greater trochanter $(3.4 \%, 14.4 \%)$, lateral epicondyle humerus $(4.7 \%, 15.1 \%)$, medial femoral condyle $(1.6 \%$, $9.2 \%)$, and quadriceps insertion superior patella $(1.5 \%, 7.0 \%)$.

Conclusion. The LEI and SPARCC enthesitis indices showed better discriminatory capacity and treatment response in patients with pSpA versus MASES, likely because these indices contain more peripheral sites. Trial registration number: ClinicalTrials.gov NCT01064856. (First Release March 15 2017; J Rheumatol 2017;44:599-608; doi:10.3899/jrheum.160387)

Key Indexing Terms:

PERIPHERAL SPONDYLOARTHRITIS

Peripheral spondyloarthritis (pSpA) is characterized by peripheral arthritis, enthesitis, and dactylitis ${ }^{1,2}$. The entheseal fibrocartilage may be the initiating site for musculoskeletal inflammation in $\mathrm{SpA}^{3,4,5}$; therefore enthesitis is an important outcome domain for axial SpA (axSpA) and pSpA, including psoriatic arthritis (PsA) ${ }^{6,7}$.

From Rheumatology Research, Swedish Medical Center, and University of Washington School of Medicine, Seattle, Washington; Department of Medicine, University of Illinois at Chicago; Immunology Clinical Development, AbbVie Inc., Chicago, Illinois, USA; Department of Rheumatology, Ghent University Hospital, Ghent, Belgium; Department of Medicine I, Rheumatology, Charité Universitätsmedizin Berlin, Berlin, Germany.

AbbVie funded the study (NCT01064856), contributed to its design, and was involved in the collection, analysis, and interpretation of the data, and in the writing, review, and approval of the publication.

P.J. Mease has received research grants and consulting fees from Amgen, Lilly, Novartis, and Pfizer. F. Van den Bosch has received consultancy and/or speaker fees from Janssen, Novartis, and UCB.

P.J. Mease, MD, Director, Rheumatology Research, Swedish Medical
ENTHESITIS

ADALIMUMAB

Different enthesitis measures have been used in axSpA and pSpA (including PsA) studies ${ }^{8,9,10}$, including the Leeds Enthesitis Index (LEI) ${ }^{11}$, the Spondyloarthritis Research Consortium of Canada (SPARCC) ${ }^{12}$ Enthesitis Index, the Maastricht Ankylosing Spondylitis Enthesitis Score $(\mathrm{MASES})^{13}$, the University of California, San Francisco

Center, and Clinical Professor, University of Washington School of Medicine; F. Van den Bosch, MD, PhD, Department of Rheumatology, Ghent University Hospital; J. Sieper, MD, PhD, Department of Medicine I, Rheumatology, Charité Universitätsmedizin Berlin; Y.Xia, PhD, Department of Medicine, University of Illinois at Chicago; A.L. Pangan, MD, Immunology Clinical Development, AbbVie Inc.; I.H. Song, MD, Immunology Clinical Development, AbbVie Inc.

Address correspondence to Dr. P.J. Mease, Seattle Rheumatology Associates, 601 Broadway, Suite 600, Seattle, Washington 98122, USA.

E-mail:pmease@philipmease.com

Full Release Article. For details see Reprints and Permissions at jrheum.org.

Accepted for publication January 18, 2017.

Personal non-commercial use only. The Journal of Rheumatology Copyright @ 2017 . All rights reserved. 
(UCSF) index ${ }^{14,15}$, and the Berlin index ${ }^{10}$. However, there is no consensus or a clear recommendation regarding which of these enthesitis indices should be used, especially in $\mathrm{pSpA}^{16,17}$. Interestingly, the MASES, which was developed to identify entheses specific for axial disease in ankylosing spondylitis (AS), has been used in several PsA clinical studies with varying levels of success ${ }^{18,19}$. More recently, the LEI and SPARCC indices were used in PsA trials, likely because they include more peripheral sites characteristic of PsA $20,21,22,23$.

In the ABILITY-2 study, we conducted the first comprehensive and detailed analysis of 3 separate tools to measure enthesitis in patients with nonpsoriatic $\mathrm{pSpA}^{24}$. The objectives of our posthoc analysis were to evaluate performance characteristics of the LEI, SPARCC, and MASES enthesitis indices in $\mathrm{pSpA}$, to evaluate specific entheses at each anatomical site location to better understand their contribution to the overall response, and to evaluate the longterm efficacy of adalimumab (ADA) on enthesitis.

\section{MATERIALS AND METHODS}

Patients. The primary results of the randomized, placebo (PBO)-controlled phase 3 ABILITY-2 (NCT01064856) study were published previously ${ }^{24}$. Eligible patients were adults with a diagnosis of pSpA who fulfilled the Assessment of SpondyloArthritis international Society criteria for $\mathrm{pSpA}^{1}$ and who had active disease defined as $\geq 1$ of the following: (1) $\geq 2$ tender and swollen joints, (2) $\geq 2$ digits with dactylitis and $\geq 1$ joint with active inflammatory arthritis not associated with dactylitis, (3) $\geq 2$ out of 29 enthesitis sites judged by a physician as severe with each site not anatomically related to the same region and without bilateral involvement of the same site, or (4) $\geq 2$ enthesitis sites and $\geq 1$ joint with active inflammatory arthritis not associated with enthesitis ${ }^{24}$. Patients with a history of psoriasis or PsA, or a present or prior diagnosis of AS as defined by the modified New York criteria, were excluded.

Patients were randomized 1:1 to ADA 40 mg every other week or PBO for 12 weeks, followed by open-label ADA $40 \mathrm{mg}$ every other week for 144 weeks. The study was performed in accordance with International Conference on Harmonisation good clinical practices and the Declaration of Helsinki. The study was approved by the ethics review board of the main institution (approving board: Western Institutional Review Board; date of approval: May 20,2010; ethics approval/site number: 4935W-10); approval was also obtained from the ethics review boards of each additional center that participated in the study. Written informed consent was obtained from all participants before study inclusion.

Enthesitis assessments. Enthesitis evaluation was based on clinical examination by independent assessors who determined the presence or absence of enthesitis at 29 different anatomical sites at baseline and at every visit. In addition, evaluation was based on patient-reported outcomes using question 4 of the Bath Ankylosing Spondylitis Disease Activity Index (BASDAI). Assessors received instruction regarding enthesitis measurement during investigator training, and investigative sites were selected based on SpA expertise. Case report forms (and the study protocol) listed all 29 entheseal sites requiring assessment, assuring systematic evaluation of all sites.

The resulting assessments were used for the calculation of the LEI (score 0-6, based on 3 bilateral sites ${ }^{11}$ ), the SPARCC Enthesitis Index (score 0-16, based on 9 bilateral sites; for scoring purposes, the inferior patella and tibial tuberosity are considered 1 site because of their anatomical proximity ${ }^{12}$ ), and the MASES (score 0-13, based on 6 bilateral sites and a single spinous process $^{13}$; Figure 1).

Statistical analyses. Correlation analyses were conducted using baseline data and using change from baseline to Week 12 data separately for each group of patients who had a baseline enthesitis index score $>0$ and for the overall population. Then, for each of the 3 enthesitis indices, the mean change from baseline to Week 12 (with corresponding 95\% CI) was compared between patients treated with ADA versus $\mathrm{PBO}$, as observed, for patients with a baseline enthesitis index score $\geq 1$. The discriminatory capacity to detect a treatment difference between $\mathrm{ADA}$ and $\mathrm{PBO}$ groups was assessed using the standardized mean difference (SMD), calculated as the difference between the group mean change for ADA and PBO from baseline to Week 12 divided by the pooled SD of the group means. The Guyatt's effect size (ES) was calculated as the mean change in the ADA group divided by the SD of the PBO group. A greater SMD and a larger Guyatt's ES represent better discriminatory capacity (SMD of $0.2,0.5$, and 0.8 represent small, medium, and large effect sizes, respectively ${ }^{25}$ ). The ability of each enthesitis index to detect change from baseline to Week 12 was determined by comparing the SMD for both treatment groups.

Individual enthesitis index analyses were performed using completer analysis. Each enthesitis site evaluated in our study was included in the analysis (locations that are bilateral were counted separately for each patient). Comparisons between the ADA and PBO groups were made for the proportion of entheseal sites that showed resolution or new onset of enthesitis from baseline to Week 12. Data were also analyzed through Week 104 to assess longterm efficacy; patients were included if they had enthesitis data at baseline and at weeks 12,52, and 104. Treatment effect over time at weeks 12,52 , and 104 was assessed by comparing patients who received ADA for 104 weeks with patients who received PBO for 12 weeks followed by open-label ADA for up to 92 weeks. All statistical analyses were performed with SAS version 9.3 (SAS Institute Inc.).

\section{RESULTS}

Patient characteristics. A total of 165 patients were randomized, 81 to $\mathrm{PBO}$ and 84 to ADA. At baseline, 143/165 $(87 \%)$ had $\geq 1$ enthesitis site, $70(83 \%)$ in the ADA group and $73(90 \%)$ in the PBO group. Demographics and baseline disease characteristics of patients with or without enthesitis at baseline are listed in Table 1. There were more patients in the group with versus the group without enthesitis (143 vs 22). Patients with enthesitis at baseline had significantly higher mean tender joint counts (TJC), swollen joint counts (SJC), and mean BASDAI scores than patients without enthesitis. In contrast, patients without enthesitis at baseline had significantly higher baseline mean high-sensitivity C-reactive protein. Question 4 of the BASDAI showed no significant difference between patients with and without enthesitis at baseline (mean values of 6.2 and 5.3, respectively).

Among patients with $\geq 1$ enthesitis site at baseline, the LEI score was $\geq 1$ in $72.0 \%$ of patients, SPARCC index in $90.2 \%$, and the MASES in $86.0 \%$. The proportion of patients with an enthesitis score $\geq 1$ and the corresponding mean baseline values were similar between ADA and PBO treatment groups (Table 2).

Correlation analyses. Among baseline values, the SJC, and in particular, the TJC had the strongest correlations among patients with LEI, MASES, or SPARCC scores $>0$ at baseline (Supplementary Table 1, left columns, available with the online version of this article). BASDAI question 4, patient's global assessment, and Health Assessment Questionnaire for Spondyloarthropathies exhibited weak to

Personal non-commercial use only. The Journal of Rheumatology Copyright (C) 2017. All rights reserved 


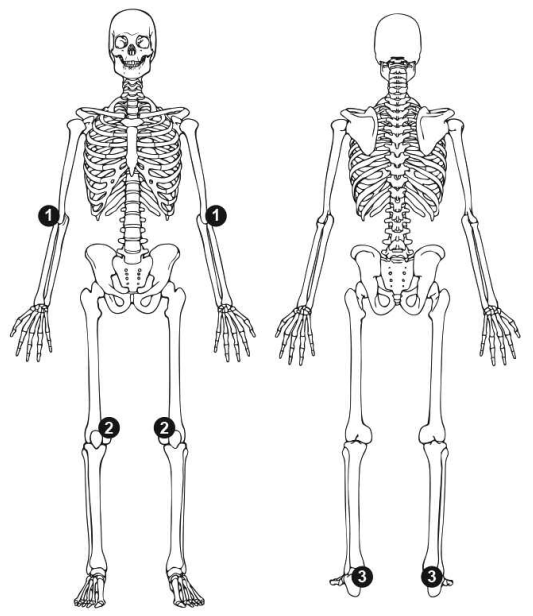

LEI

6 sites

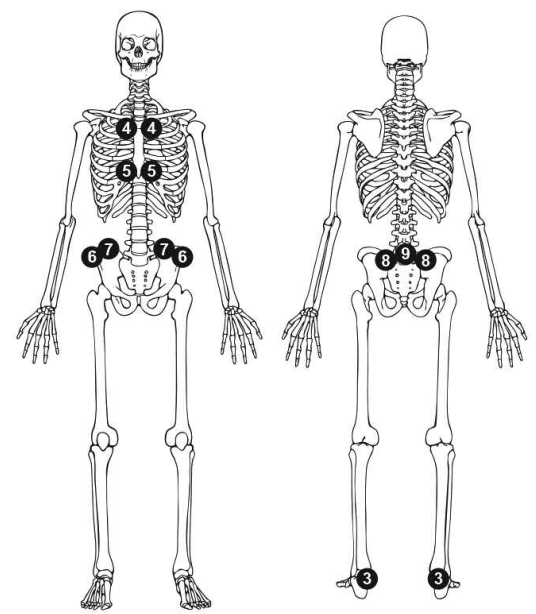

MASES 13 sites

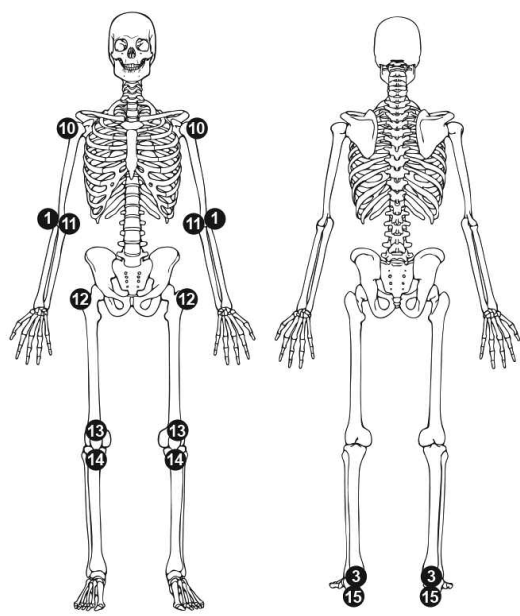

SPARCC

18 sites, score of $16^{*}$

(1) Lateral epicondyle humerus
2 Medial condyle femur
(3) Achilles tendon
(4) $1^{\text {st }}$ costochondral
(5 $7^{\text {th }}$ costochondral

6 Anterior superior iliac spine (7) Iliac crest

8 Posterior superior iliac spine $95^{\text {th }}$ lumbar spinous process (10) Supraspinatus insertion

(11) Medial epicondyle humerus

(12) Greater trochanter

(13) Quadriceps insertion into superior border of patella

(14) Patellar tendon insertion into inferior pole of patella OR tibial tubercle* (15) Insertion plantar fascia

Figure 1. Enthesitis sites evaluated by each instrument. * For scoring purposes, the inferior patella and tibial tuberosity are considered 1 site because of their anatomical proximity. LEI: Leeds Enthesitis Index; MASES: Maastricht Ankylosing Spondylitis Enthesitis Score; SPARCC: Spondyloarthritis Research Consortium of Canada.

Table 1. Baseline demographics and disease characteristics. Values are mean (SD) unless otherwise specified.

\begin{tabular}{|c|c|c|c|}
\hline Characteristics & $\begin{array}{c}\text { Patients With } \geq 1 \\
\text { Enthesitis Site, } n=143\end{array}$ & $\begin{array}{c}\text { Patients With } 0 \\
\text { Enthesitis Sites, } \mathrm{n}=22\end{array}$ & $\mathrm{p}$ \\
\hline Age, yrs & $40.5(12.0)$ & $41.0(12.0)$ & 0.854 \\
\hline Female, n (\%) & $78(54.5)$ & $12(54.5)$ & 1.000 \\
\hline HLA-B27+, n (\%) & $85(59.4)$ & $15(68.2)$ & 0.641 \\
\hline SpA symptom duration, yrs & $7.2(7.2)^{\#}$ & $7.3(7.0)$ & 0.996 \\
\hline $\mathrm{SJC76} \geq 1, \mathrm{n}(\%)$ & $132(92.3)$ & $22(100)$ & 0.363 \\
\hline SJC76 & $7.0(7.3)$ & $4.8(3.1)$ & $0.018^{*}$ \\
\hline TJC78 $\geq 1, \mathrm{n}(\%)$ & $141(98.6)$ & $22(100)$ & 1.000 \\
\hline TJC78 & $14.4(15.2)$ & $6.1(3.8)$ & $<0.001 *$ \\
\hline Elevated hsCRP, n (\%) & $57(39.9)$ & $15(68.2)$ & $0.020 *$ \\
\hline hsCRP, mg/ $1^{\dagger}$ & $8.7(14.7)$ & $20.3(24.5)$ & $0.040^{*}$ \\
\hline BASDAI, 0-10 & $5.8(1.6)$ & $4.5(1.4)$ & $<0.001 *$ \\
\hline BASDAI question $3^{\ddagger}$ & $6.7(1.8)$ & $6.3(2.2)$ & 0.417 \\
\hline BASDAI question $4^{\S}$ & $6.2(2.3)$ & $5.3(2.3)$ & 0.105 \\
\hline
\end{tabular}

$* \mathrm{p} \leq 0.05$ for patients with versus without $\geq 1$ enthesitis site at baseline. ${ }^{\#} \mathrm{n}=139$. ${ }^{\dagger}$ Upper limit of normal $=$ $5 \mathrm{mg} / \mathrm{l}$. ${ }^{\ddagger}$ How would you describe the overall level of pain/swelling in joints, other than neck, back, or hips, you have had? ${ }^{\S}$ How would you describe the overall level of discomfort you have had from any areas tender to touch or pressure? SpA: spondyloarthritis; SJC: swollen joint count; TJC: tender joint count; hsCRP: high-sensitivity C-reactive protein; BASDAI: Bath Ankylosing Spondylitis Disease Activity Index.

moderate correlations at best. Among values for changes from baseline to Week 12, again SJC and TJC had the strongest correlations (Supplementary Table 1, right columns, available with the online version of this article). However, the magnitude was generally lower compared with correlations with baseline scores. Similar results were observed for the overall population (data not shown).
Discriminatory capacity and treatment response. Among patients with $\geq 1$ enthesitis site at baseline, significant improvement from baseline to Week 12 was observed with ADA compared with PBO treatment in overall LEI (-68\% vs $-21 \%$, respectively, $\mathrm{p}=0.0001)$ and SPARCC (-50\% vs $-15 \%, \mathrm{p}=0.0011)$ enthesitis indices, but not in the MASES index $(-32 \%$ vs $-28 \%, \mathrm{p}=0.2882)$.

Personal non-commercial use only. The Journal of Rheumatology Copyright (c) 2017. All rights reserved. 
Table 2. Number (percentage) of patients with $\geq 1$ positive enthesitis site at baseline $(n=143)$ and mean enthesitis scores among patients with baseline score $\geq 1$ in individual enthesitis indices.

\begin{tabular}{lcc}
\hline Variables & $\begin{array}{c}\text { Placebo, } \\
\mathrm{n}=73\end{array}$ & $\begin{array}{c}\text { Adalimumab, } \\
\mathrm{n}=70\end{array}$ \\
\hline $\mathrm{LEI} \geq 1, \mathrm{n}(\%)$ & $51(70)$ & $52(74)$ \\
LEI, 0-6, mean (SD) & $2.3(1.5)$ & $2.4(1.5)$ \\
SPARCC Enthesitis Index $\geq 1, \mathrm{n}(\%)$ & $65(89)$ & $64(91)$ \\
SPARCC Enthesitis Index, 0-16, mean (SD) & $5.1(3.6)$ & $5.0(3.9)$ \\
MASES $\geq 1, \mathrm{n}(\%)$ & $65(89)$ & $58(83)$ \\
MASES, 0-13, mean (SD) & $4.5(3.2)$ & $4.5(3.5)$ \\
\hline
\end{tabular}

LEI: Leeds Enthesitis Index; MASES: Maastricht Ankylosing Spondylitis Enthesitis Score; SPARCC: Spondyloarthritis Research Consortium of Canada.
The LEI and SPARCC enthesitis scores showed higher discriminatory ability and treatment response between ADA treatment and PBO at Week 12 compared with the MASES. Unlike the MASES, 95\% CI for mean change from baseline to Week 12 did not overlap for the LEI and SPARCC indices in ADA- and PBO-treated patients who had a baseline enthesitis score $\geq 1$ (Figure $2 \mathrm{~A}$ and Figure 2B). Additionally, among patients with an enthesitis index score $\geq 1$, larger SMD were observed for the LEI $(-0.73)$ and SPARCC $(-0.56)$ enthesitis indices compared with the MASES $(-0.32)$. Similarly, Guyatt's ES was greater for the LEI (-1.07) and SPARCC (-0.99) enthesitis indices than for the MASES $(-0.81)$.

Individual enthesitis site analysis. To analyze why the LEI

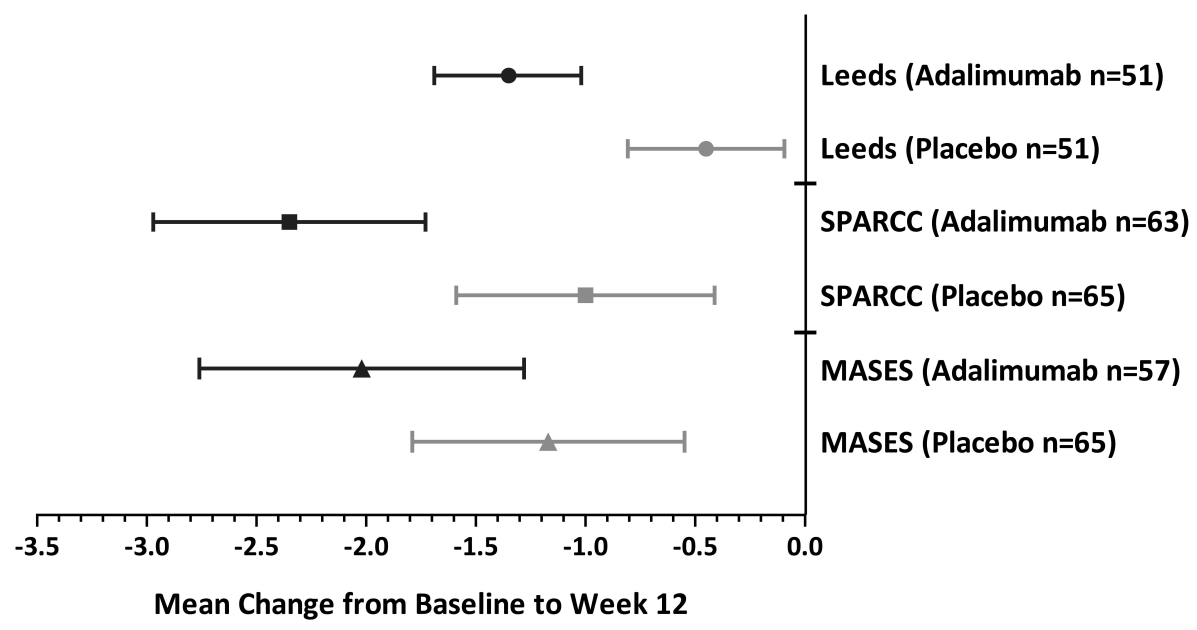

B

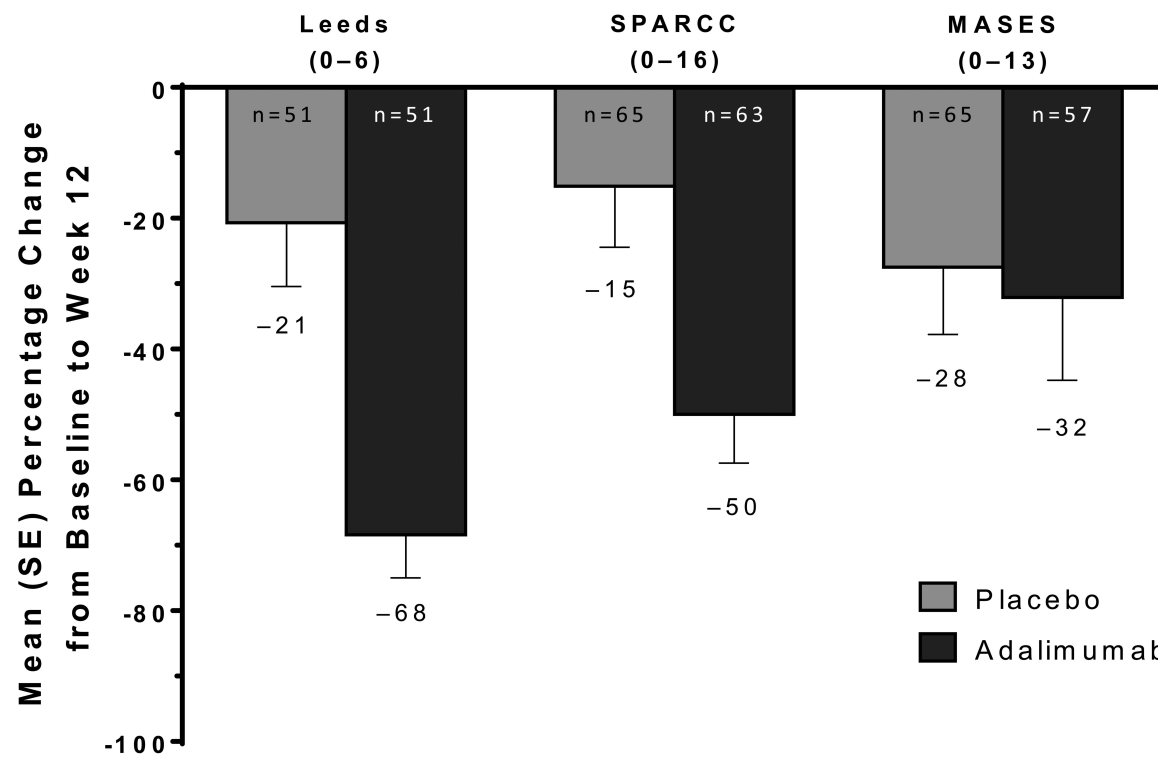

Figure 2. (A) Mean (95\% CI) change and (B) mean percentage (SE) change in enthesitis scores (Leeds Enthesitis Index, SPARCC Enthesitis Index, and MASES) from baseline to Week 12 among patients with a baseline enthesitis score $\geq 1$ by treatment (observed data). SE: standard error; MASES: Maastricht Ankylosing Spondylitis Enthesitis Score; SPARCC: Spondyloarthritis Research Consortium of Canada. 
and SPARCC enthesitis indices performed better than the MASES in discriminatory capacity and treatment response and to understand which specific sites are responsible for the response, enthesitis at each individual anatomical site was evaluated.
We first performed the individual anatomical site analysis in all patients (with or without enthesitis at baseline). At Week 12, among the 82 patients receiving ADA, the number of positive enthesitis sites at the Achilles tendon, for example, decreased by $>50 \%$ (from a total of 53 sites to 25 sites,
A.

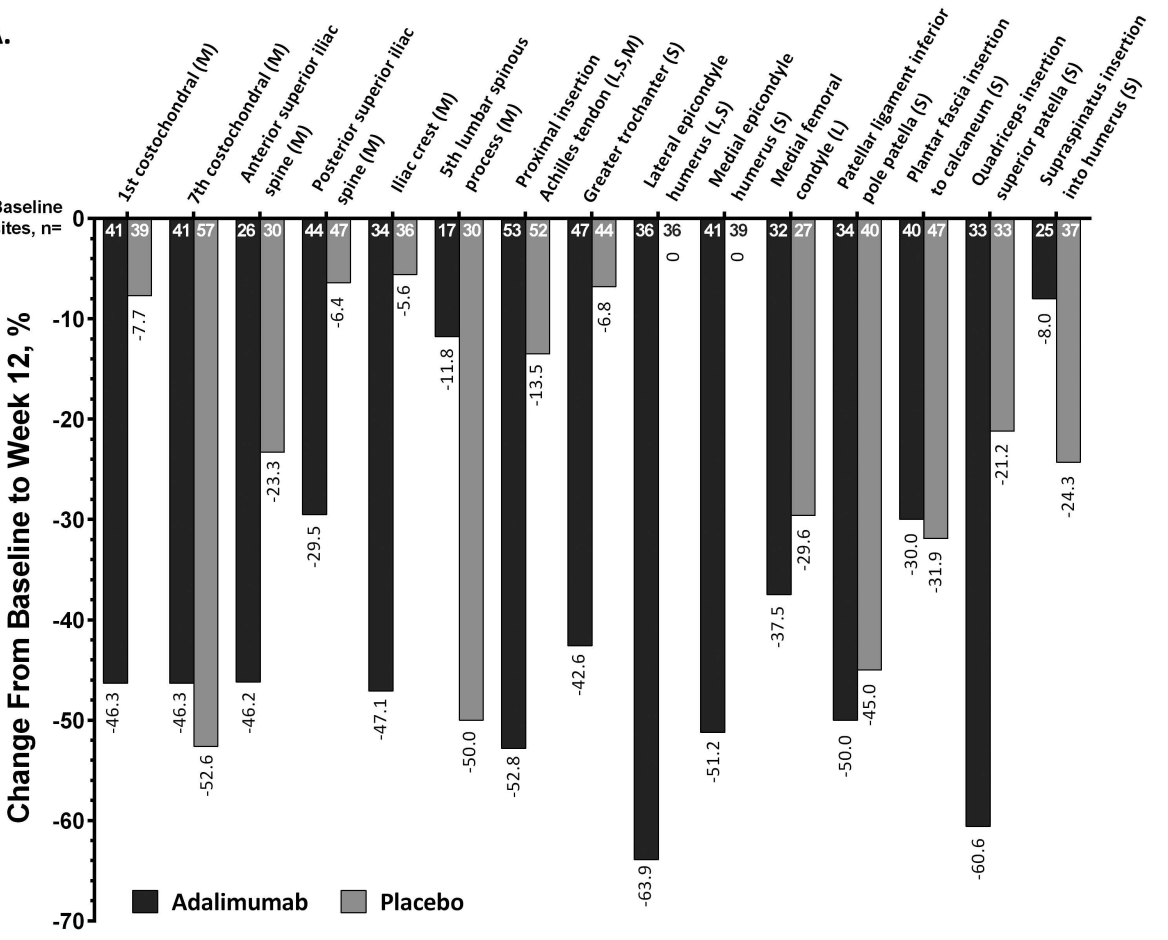

B.

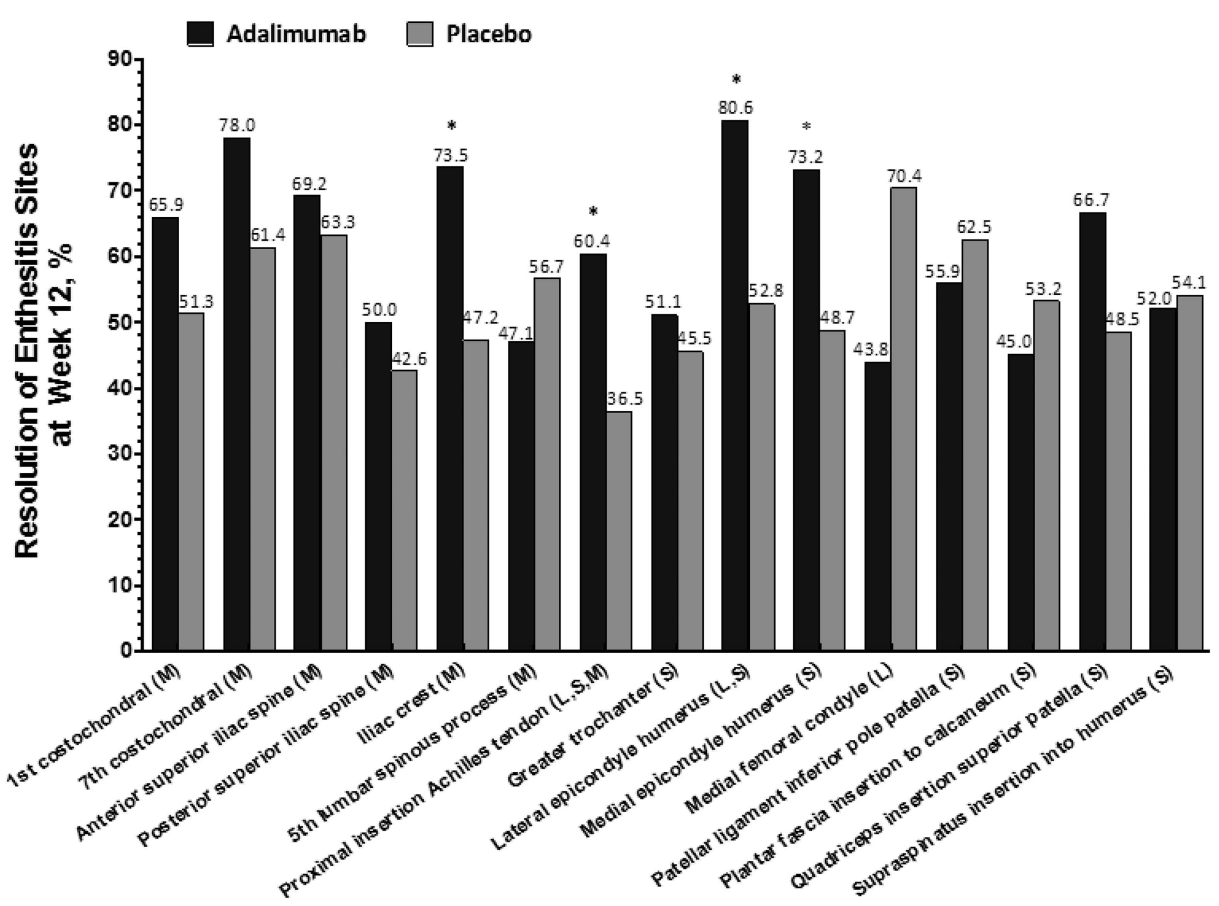

Figure 3. Individual enthesitis site analyses in patients with available data at baseline and Week 12. (A) Percentage change from baseline in number of enthesitis sites at Week 12 for the overall population. For example, among 82 patients treated with adalimumab, the number of positive enthesitis sites at the Achilles tendon decreased from 53 at baseline to 22 at Week 12, which represents a $52.8 \%$ decrease; in patients treated with placebo, the decrease was from 52 to 45 sites (13.5\% decrease). (B) Proportion of enthesitis sites with resolution of enthesitis at Week 12 among sites with enthesitis at baseline. 


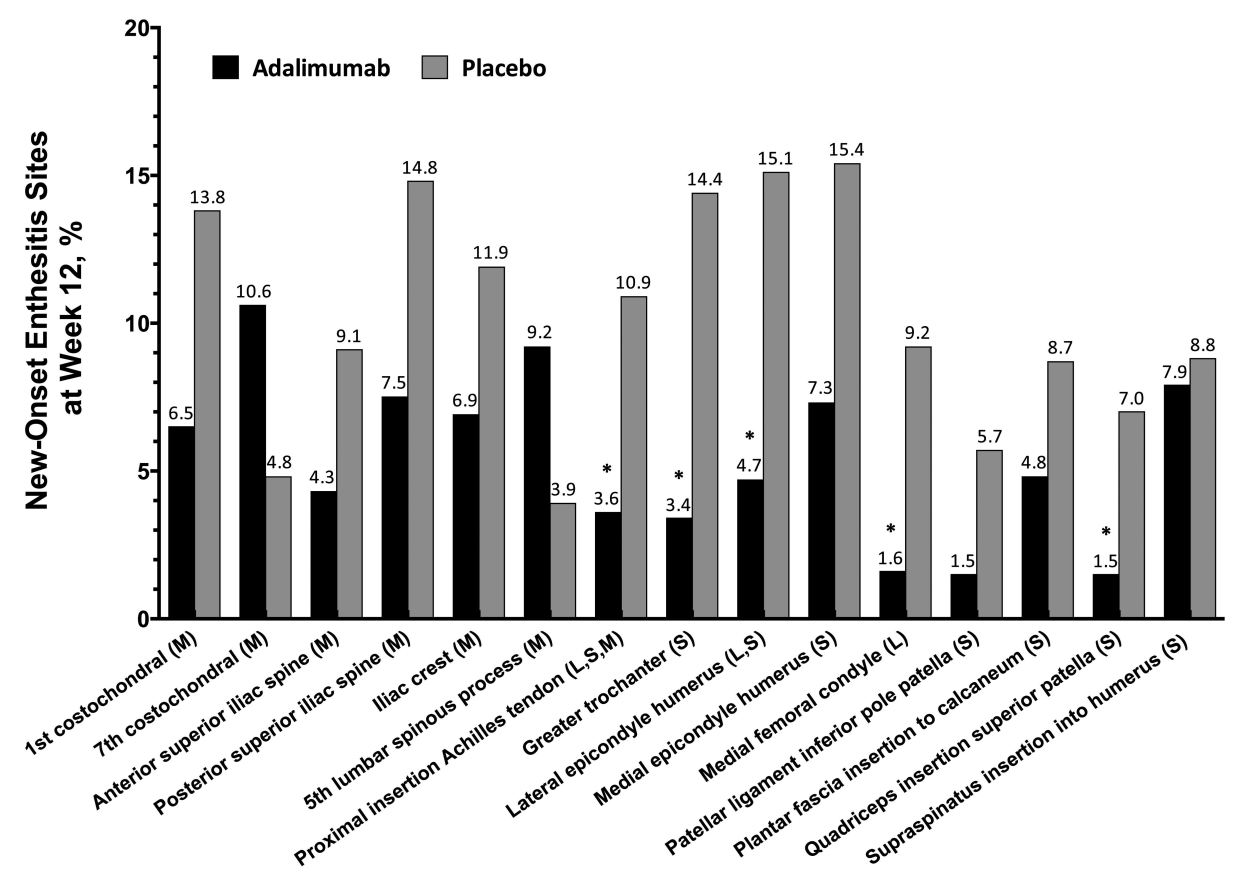

Figure 3. (C) Proportion of sites with new-onset enthesitis at Week 12 among sites with no enthesitis at baseline. ${ }^{*} \mathrm{p}<0.05$, adalimumab vs placebo. L: Leeds Enthesitis Index; M: Maastricht Ankylosing Spondylitis Enthesitis Score; S: Spondyloarthritis Research Consortium of Canada Enthesitis Index.

change of 52.8\%), whereas among the 81 patients receiving $\mathrm{PBO}$, the corresponding decrease was only $13.5 \%$ (from 52 to 45 sites; Figure 3A). In contrast, a large difference between treatments was not observed at the seventh costochondral junction, where the number of positive enthesitis sites decreased by $46.3 \%$ (from 41 to 22 sites) in patients treated with ADA versus a higher decrease of $52.6 \%$ (from 57 to 27 sites) in patients treated with PBO. Similar to the Achilles tendon, further individual enthesitis site analyses suggested that percentage changes from baseline to Week 12 for patients treated with $\mathrm{ADA}$ and $\mathrm{PBO}$ at the greater trochanter $(42.6 \%$ vs $6.8 \%)$, lateral epicondyle humerus ( $63.9 \%$ vs $0 \%)$, and medial epicondyle humerus (51.2\% vs $0 \%$ ) have numerically higher discriminatory capacity compared with other more axial sites (Figure 3A). The iliac crest, which is part of the MASES that measures axial disease, also showed discriminatory capacity ( $47.1 \%$ vs $5.6 \%$ ).

We were then further interested in whether better discriminatory capacity of certain sites in all patients could be explained by greater resolution (disappearance) of enthesitis sites that were positive at baseline, but were subsequently negative at Week 12 in ADA- versus PBO-treated patients. Indeed, among positive enthesitis sites at baseline, a significantly greater proportion resolved at Week 12 in patients treated with ADA compared with PBO in the Achilles tendon $(60.4 \%$ vs $36.5 \%$, respectively, $\mathrm{p}=0.019)$, medial epicondyle ( $73.2 \%$ vs $48.7 \%, p=0.038)$, lateral epicondyle ( $80.6 \%$ vs
$52.8 \%, \mathrm{p}=0.023)$, and the iliac crest $(73.5 \%$ vs $47.2 \%$, $\mathrm{p}=0.030 ;$ Figure 3B).

We then assessed new-onset enthesitis among entheseal sites that were negative at baseline, but were subsequently positive at Week 12 in ADA- versus PBO-treated patients. Significantly less new-onset enthesitis was observed in patients treated with ADA compared with $\mathrm{PBO}$ at peripheral locations common to the LEI and SPARCC enthesitis indices: the Achilles tendon ( $3.6 \%$ vs $10.9 \%, \mathrm{p}=0.041)$, greater trochanter $(3.4 \%$ vs $14.4 \%, \mathrm{p}=0.005)$, lateral epicondyle humerus $(4.7 \%$ vs $15.1 \%, \mathrm{p}=0.006)$, medial femoral condyle $(1.6 \%$ vs $9.2 \%, \mathrm{p}=0.009)$, and quadriceps insertion superior patella ( $1.5 \%$ vs $7.0 \%, p=0.034$; Figure $3 \mathrm{C})$. In contrast, the seventh costochondral joint and the fifth lumbar spinous process (both part of the MASES) had higher rates of new-onset enthesitis in patients treated with ADA compared with $\mathrm{PBO}$ (10.6\% vs $4.8 \%$ and $9.2 \%$ vs $3.9 \%$, respectively); however, differences were not statistically significant. Generally, the rate of new-onset enthesitis was lower in patients treated with ADA (mostly $<10.0 \%$, with most sites between $1.5 \%$ and about $7.0 \%$ ) compared with PBO.

To summarize these findings, for the overall individual enthesitis site analysis, the most consistent and best responses were observed for the Achilles tendon and lateral epicondyle humerus. The medial epicondyle humerus, greater trochanter, and iliac crest also demonstrated good responses.

Longterm efficacy. To understand how enthesitis at each

Personal non-commercial use only. The Journal of Rheumatology Copyright $@$ 2017. All rights reserved. 
anatomical site evolves beyond the 12-week, double-blind period and with longterm ADA treatment, patients completing Week 104 of our study were assessed by the original treatment group. Analysis of individual enthesitis sites over time in patients continuously treated with ADA demonstrated a sustained treatment effect from baseline to Week 12, and with further improvement at weeks 52 and 104
(Figure 4A). Interestingly, this effect was independent of whether enthesitis sites were part of the LEI, SPARCC, or MASES indices. In patients who initially received $\mathrm{PBO}$ and then switched to open-label ADA at Week 12, marked improvement occurred at weeks 52 and 104 (Figure 4B). Notably, in patients treated with PBO, some sites (Achilles tendon, greater trochanter, lateral epicondyle humerus, and
A.

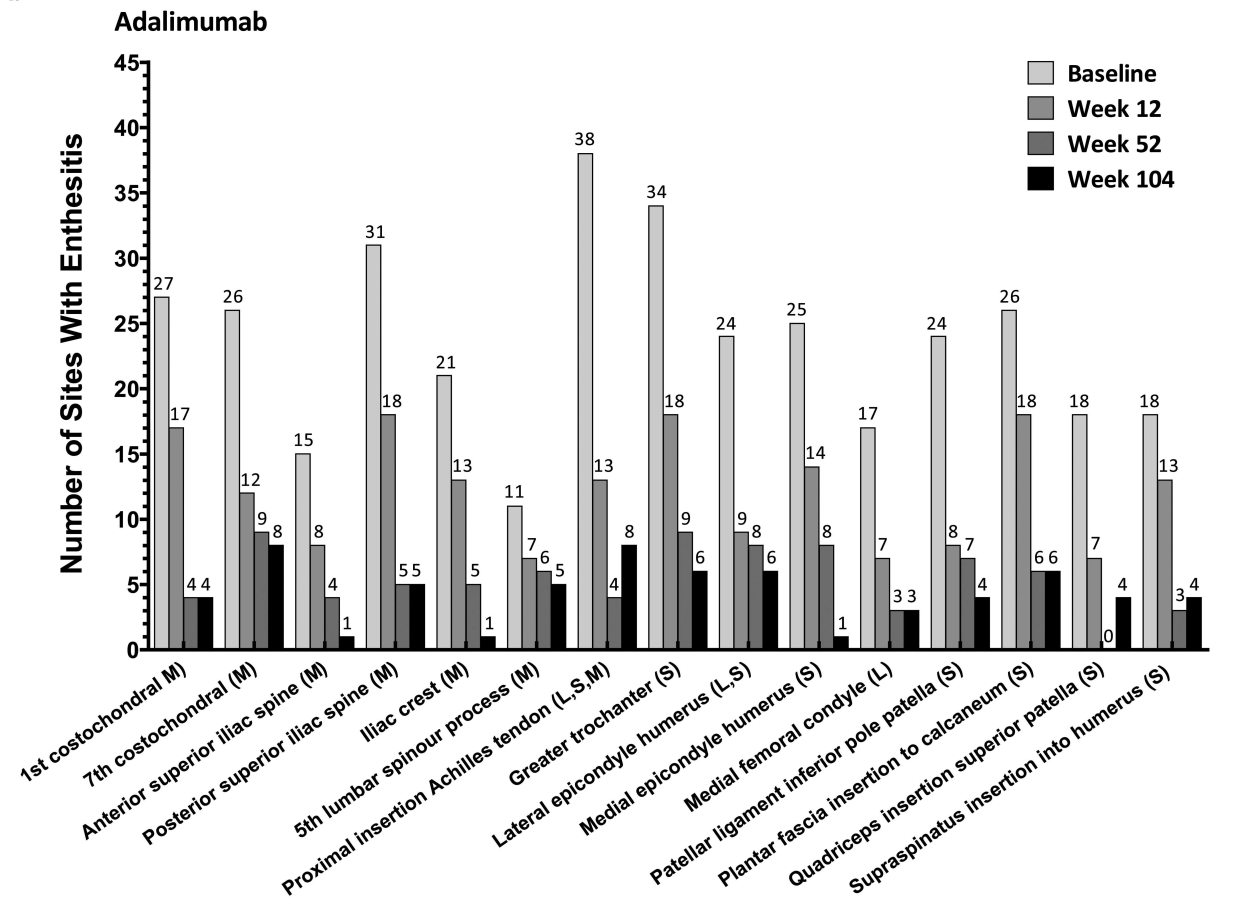

B.

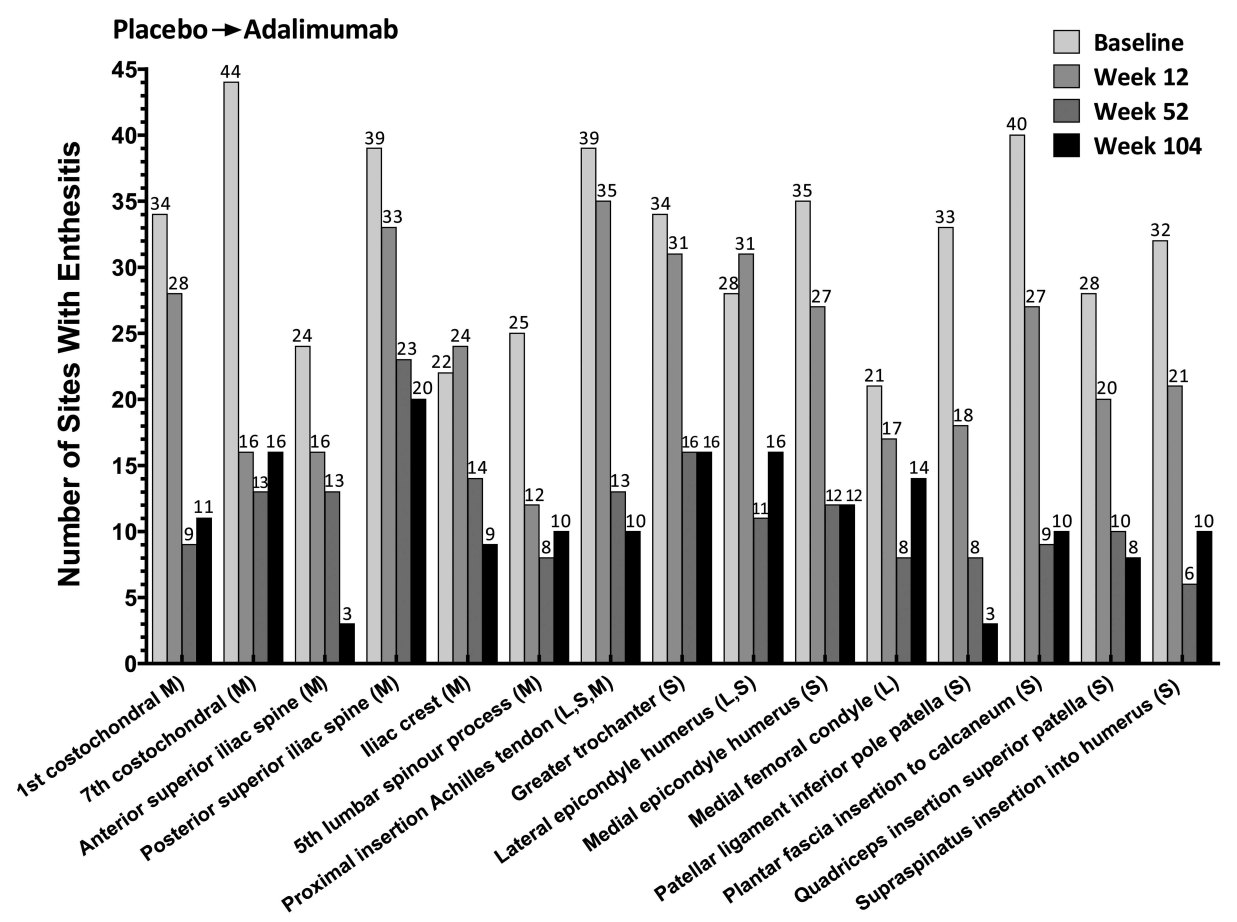

Figure 4. Treatment effect on individual enthesitis sites through Week 104 in patients with available data at baseline and weeks 12,52, and 104. Sites with enthesitis shown for (A) patients treated with adalimumab for 104 weeks and (B) patients treated with placebo for 12 weeks followed by 92 weeks of adalimumab treatment. L: Leeds Enthesitis Index; M: Maastricht Ankylosing Spondylitis Enthesitis Score; S: Spondyloarthritis Research Consortium of Canada Enthesitis Index. 
medial femoral condyle) demonstrated little change between baseline and Week 12 (as would be expected during treatment with PBO), but showed marked, sustained improvement after initiation of ADA at Week 12. This further underlines the discriminatory capacity of these sites. When examining all sites in the Week 104 completers, no single enthesitis site showed worsening at the group level during sustained ADA treatment.

Notably, beyond the 12-week double-blind period, overall enthesitis scores for each instrument (LEI, SPARCC, and MASES) were improved with longterm ADA treatment (up to Week 104; Supplementary Figure 1, available with the online version of this article). Differences in least-squares means became smaller over time between patients initially treated with $\mathrm{PBO}$ and those initially treated with ADA, but the former group did not improve to the level achieved by patients continuously treated with ADA.

\section{DISCUSSION}

ABILITY-2 is the first study, to our knowledge, offering the unique opportunity to compare the LEI, SPARCC, and MASES enthesitis indices in the setting of a prospective randomized PBO-controlled trial. To our knowledge, our current study is the only analysis conducted to date that provides a detailed and comprehensive comparison of 3 different tools to evaluate enthesitis. Enthesitis scores correlated best with the TJC at baseline, but less well for change to Week 12 scores, indicating that the enthesitis tools measure different disease activity aspects compared with tenderness in joints. In contrast, BASDAI question 4, which is supposed to measure disease activity caused by enthesitis, showed only weak correlation with the clinical enthesitis tools. BASDAI question 4 is perceived to be insufficiently specific, and notably was not included (although other BASDAI questions were) into the Ankylosing Spondylitis Disease Activity Score (ASDAS). The ASDAS, a disease activity index in AS, aims to be truthful, discriminative, and feasible, as well as inclusive of domains/items that are considered relevant by patients and doctors ${ }^{26}$.

The LEI and SPARCC indices had better discriminatory capacity and treatment response than the MASES in patients with $\mathrm{pSpA}$ treated with ADA. When assessed by individual location, enthesitis sites with higher discriminatory capacity were predominantly in peripheral sites that are more common to the LEI and SPARCC indices. Better discrimination can be explained by a combination of more frequent resolution of existing enthesitis sites and fewer new-onset enthesitis sites at certain locations with ADA treatment. Additionally, the higher discriminatory capacity of certain enthesitis sites is further supported by longterm data showing that these sites are also responsive after switching from PBO to active treatment and show consistent efficacy, without worsening, over 2 years. Of note, lack of discrimination at some other sites is not because of poor response in the ADA group, but mainly because of resolution/improvement of enthesitis at these sites in the PBO group. The exact reason for this PBO response remains unclear, but could be explained by spontaneous improvement, measurement variability, or limitations in specificity and the subjective characteristic of existing enthesitis measures, particularly for sites at which the presence of enthesitis relies on a patient's report of pain with pressure (i.e., swelling or inflammation is not easily detected by physical examination).

Overall, these findings explain the better performance of the LEI and SPARCC enthesitis indices in patients with pSpA compared with the MASES, which evaluates fewer peripheral sites. This is of clinical relevance because there is currently no consensus or recommendation regarding which enthesitis scoring system should be used to monitor outcomes in patients with $\mathrm{pSpA}^{16,17}$. Our findings also provide insight into which sites and scores may be most useful.

Only a few other studies have compared different enthesitis indices. In a study of AS, the 17-point UCSF index performed best for detecting a treatment effect during treatment with golimumab versus PBO, although the MASES also performed reasonably well ${ }^{8}$. Of note, there was no detailed analysis by anatomical site in the study or comparison of the MASES or UCSF index, which have proportionately more axial entheses sites, with indices that primarily include peripheral sites.

Some phase III studies in patients with PsA used the MASES with varied success. The MASES showed inconsistent performance in terms of discriminatory properties in 3 trials of apremilast in PsA; no clear dose response was evident, and only 1 of 6 dose arms showed significant improvement versus $\mathrm{PBO}^{18}$. The lack of clear, evidence-based recommendations for enthesitis tools may explain the use of a modified MASES in a phase III trial of ustekinumab in PsA; in this version, the insertions of the plantar fascia-peripheral enthesitis sites were included along with the original MASES sites ${ }^{19}$. Using this PsA-modified MASES, ustekinumab $90 \mathrm{mg}$ significantly improved enthesitis at Week 24 compared with PBO (median percentage change $48 \%$ vs $0 \%$, respectively, $\mathrm{p}<0.01)^{19}$.

The LEI has been used effectively in several PsA trials $^{21,23}$. For example, 24 weeks of secukinumab treatment led to complete resolution of enthesitis in about $42 \%-48 \%$ of patients who had enthesitis at baseline, compared with $22 \%$ of PBO-treated patients $(\mathrm{p}<0.01)^{23}$. Another study showed a statistically significant effect on mean change from baseline for certolizumab versus $\mathrm{PBO}^{21}$.

Interestingly, 1 study in patients with PsA evaluated the efficacy of various doses of clazakizumab versus $\mathrm{PBO}$ using both the LEI and SPARCC enthesitis indices ${ }^{20}$. In the study, the SPARCC Enthesitis Index was discriminant in the lowest dose group of clazakizumab, whereas the LEI was not ${ }^{20}$, possibly because more sites are assessed in the SPARCC index. In other ongoing PsA studies, both the LEI and

Personal non-commercial use only. The Journal of Rheumatology Copyright @ 2017. All rights reserved. 
SPARCC are also being used, which will allow further evaluation of their relative performance characteristics (Mease, personal communication).

The findings in our study could potentially be extrapolated to PsA for several reasons. First, patients with nonpsoriatic pSpA and patients with PsA both belong to the SpA group with predominant peripheral manifestations sharing common clinical and genetic features ${ }^{1,2}$. Second, the degree of improvements in enthesitis burden (mean change from baseline or percentage improvement or resolution of enthesitis) observed in our trial is comparable with that observed in patients with PsA ${ }^{19,21,23}$. Third, an imaging study comparing magnetic resonance imaging (MRI) and clinical examination showed similar enthesitis patterns (similar frequencies of enthesitis on MRI compared with clinical examination) in patients with PsA and $\mathrm{SpA}^{27}$. Finally, the detailed site analysis in our study provides a plausible explanation as to why the LEI and SPARCC enthesitis indices showed a better interobserver agreement and overall better performance than the MASES in a PsA study performed several years ago (the INSPIRE study $)^{28}$. Further studies are needed for confirmation.

A limitation of our analysis is that only clinical examinations without imaging were performed. Clinical assessment of enthesitis and the presence of tenderness and swelling are sometimes regarded as difficult and nonspecific. Also, differences in the reliability of the assessment of certain entheses could have influenced proper evaluation of responsiveness to change or discrimination. Tenderness on palpation or pain at entheseal sites may be related to other reasons for having tender entheses, such as mechanical stress/overuse, trauma, degeneration, or metabolic disease ${ }^{29}$. However, our study, which involved numerous investigators across several countries, showed consistent results. Clinically, it is reasonable that some sites might be prone to enthesitis resolution or new-onset enthesitis during ADA versus PBO treatment.

Imaging was not used to confirm the clinical findings in our analysis. In the absence of a gold standard for diagnosis, it is unclear whether imaging is a better tool than clinical assessment ${ }^{27,29,30,31,32,33,34,35}$. Outside the clinical trial setting, a combination of clinical suspicion and physical examination plus an objective assessment of inflammation (by ultrasound or MRI) would aid in the proper diagnosis of enthesitis, as well as choice of therapy.

Based on the results of our analyses, in clinical practice, it may be more reliable for physicians to assess entheses that showed a more consistent response to treatment in patients with $\mathrm{pSpA}$, such as the Achilles tendon (included in all 3 enthesitis indices assessed), the lateral and medial epicondyle humerus, the greater trochanter, and the iliac crest. Further, rheumatologists may want to exercise caution when basing treatment decisions on entheses that appear to be more prone to fluctuation, such as the seventh costochondral joint or the supraspinatus to humerus. When examining individual enthe- sitis sites, it is important to note that the Achilles tendon, included in all 3 enthesitis tools used in our study, showed an overall good performance. Confirmation of our findings in another dataset is warranted.

The LEI and SPARCC enthesitis indices showed better discriminatory capacity and treatment response compared with the MASES in patients with nonpsoriatic pSpA treated with ADA. Continuous treatment with ADA for 2 years resulted in a sustained improvement of all enthesitis sites measured by the 3 enthesitis measures.

\section{ACKNOWLEDGMENT}

The authors thank Nupun A. Varothai, PhD, formerly of AbbVie, and Sheng Zhong, $\mathrm{PhD}$, of AbbVie, for their contributions to the statistical analysis and manuscript. Medical writing support was provided by Kathleen V. Kastenholz, PharmD, MS, of AbbVie, and Katherine Groschwitz, PhD, of Complete Publication Solutions LLC (North Wales, Pennsylvania, USA).

\section{ONLINE SUPPLEMENT}

Supplementary material accompanies the online version of this article.

\section{REFERENCES}

1. Rudwaleit M, van der Heijde D, Landewé R, Akkoc N, Brandt J, Chou CT, et al. The Assessment of SpondyloArthritis International Society classification criteria for peripheral spondyloarthritis and for spondyloarthritis in general. Ann Rheum Dis 2011;70:25-31.

2. Dougados M, Baeten D. Spondyloarthritis. Lancet 2011; 377:2127-37.

3. Sherlock JP, Joyce-Shaikh B, Turner SP, Chao CC, Sathe M, Grein $\mathrm{J}$, et al. IL-23 induces spondyloarthropathy by acting on ROR- $\gamma \mathrm{t}+$ CD3+CD4-CD8- entheseal resident T cells. Nat Med 2012; 18:1069-76.

4. Lories RJ, McInnes IB. Primed for inflammation: enthesis-resident T cells. Nat Med 2012;18:1018-9.

5. Benjamin M, McGonagle D. The enthesis organ concept and its relevance to the spondyloarthropathies. Adv Exp Med Biol 2009;649:57-70.

6. Sieper J, Rudwaleit M, Baraliakos X, Brandt J, Braun J, Burgos-Vargas R, et al. The Assessment of SpondyloArthritis international Society (ASAS) handbook: a guide to assess spondyloarthritis. Ann Rheum Dis 2009;68 Suppl 2:ii1-44.

7. Gladman DD, Mease PJ, Strand V, Healy P, Helliwell PS, Fitzgerald $\mathrm{O}$, et al. Consensus on a core set of domains for psoriatic arthritis. J Rheumatol 2007;34:1167-70.

8. van der Heijde D, Braun J, Deodhar A, Inman RD, Xu S, Mack ME, et al. Comparison of three enthesitis indices in a multicentre, randomized, placebo-controlled trial of golimumab in ankylosing spondylitis (GO-RAISE). Rheumatology 2013;52:321-5.

9. van der Heijde D, Kivitz A, Schiff MH, Sieper J, Dijkmans BA, Braun J, et al; ATLAS Study Group. Efficacy and safety of adalimumab in patients with ankylosing spondylitis: results of a multicenter, randomized, double-blind, placebo-controlled trial. Arthritis Rheum 2006;54:2136-46.

10. Braun J, Brandt J, Listing J, Zink A, Alten R, Golder W, et al. Treatment of active ankylosing spondylitis with infliximab: a randomised controlled multicentre trial. Lancet 2002;359:1187-93.

11. Healy PJ, Helliwell PS. Measuring clinical enthesitis in psoriatic arthritis: assessment of existing measures and development of an instrument specific to psoriatic arthritis. Arthritis Rheum 2008;59:686-91

12. Maksymowych WP, Mallon C, Morrow S, Shojania K, Olszynski WP, Wong RL, et al. Development and validation of the

Personal non-commercial use only. The Journal of Rheumatology Copyright (C) 2017. All rights reserved. 
Spondyloarthritis Research Consortium of Canada (SPARCC) Enthesitis Index. Ann Rheum Dis 2009;68:948-53.

13. Heuft-Dorenbosch L, Spoorenberg A, van Tubergen A, Landewé R, van ver Tempel $\mathrm{H}$, Mielants $\mathrm{H}$, et al. Assessment of enthesitis in ankylosing spondylitis. Ann Rheum Dis 2003;62:127-32.

14. Clegg DO, Reda DJ, Weisman MH, Blackburn WD, Cush JJ, Cannon GW, et al. Comparison of sulfasalazine and placebo in the treatment of ankylosing spondylitis. A Department of Veterans Affairs Cooperative Study. Arthritis Rheum 1996;39:2004-12.

15. Gorman JD, Sack KE, Davis JC Jr. Treatment of ankylosing spondylitis by inhibition of tumor necrosis factor alpha. N Engl J Med 2002;346:1349-56.

16. Mease PJ. Measures of psoriatic arthritis: Tender and Swollen Joint Assessment, Psoriasis Area and Severity Index (PASI), Nail Psoriasis Severity Index (NAPSI), Modified Nail Psoriasis Severity Index (mNAPSI), Mander/Newcastle Enthesitis Index (MEI), Leeds Enthesitis Index (LEI), Spondyloarthritis Research Consortium of Canada (SPARCC), Maastricht Ankylosing Spondylitis Enthesis Score (MASES), Leeds Dactylitis Index (LDI), Patient Global for Psoriatic Arthritis, Dermatology Life Quality Index (DLQI), Psoriatic Arthritis Quality of Life (PsAQOL), Functional Assessment of Chronic Illness Therapy-Fatigue (FACIT-F), Psoriatic Arthritis Response Criteria (PsARC), Psoriatic Arthritis Joint Activity Index (PsAJAI), Disease Activity in Psoriatic Arthritis (DAPSA), and Composite Psoriatic Disease Activity Index (CPDAI). Arthritis Care Res 2011;63 Suppl 11:S64-85.

17. Helliwell PS. Assessment of disease activity in psoriatic arthritis. Clin Exp Rheumatol 2015;33 Suppl 93:S44-7.

18. Kavanaugh A, Cutolo M, Mease PJ, Gladman DD, Adebajo AO, Gomez-Reino J, et al. Apremilast, an oral phosphodiesterase 4 inhibitor, is associated with long-term (52-week) improvement in measures of disease activity in patients with psoriatic arthritis: results from 3 phase 3, randomized, controlled trials [abstract]. Arthritis Rheum 2014;66 Suppl 11:S239.

19. Ritchlin C, Rahman P, Kavanaugh A, McInnes IB, Puig L, Li S, et al. Efficacy and safety of the anti-IL-12/23 p40 monoclonal antibody, ustekinumab, in patients with active psoriatic arthritis despite conventional non-biological and biological anti-tumour necrosis factor therapy: 6-month and 1-year results of the phase 3, multicentre, double-blind, placebo-controlled, randomised PSUMMIT 2 trial. Ann Rheum Dis 2014;73:990-9.

20. Mease PJ, Gottlieb AB, Berman A, Drescher E, Xing J, Banerjee S, et al. A phase IIb, randomized, double-blind, placebo-controlled, dose-ranging, multicenter study to evaluate the efficacy and safety of clazakizumab, an anti-IL-6 monoclonal antibody, in adults with active psoriatic arthritis [abstract]. Arthritis Rheumatol 2014;66 Suppl 11:S423.

21. Mease PJ, Fleischmann R, Deodhar AA, Wollenhaupt J, Khraishi M, Kielar D, et al. Effect of certolizumab pegol on signs and symptoms in patients with psoriatic arthritis: 24-week results of a Phase 3 double-blind randomised placebo-controlled study (RAPID-PsA). Ann Rheum Dis 2014;73:48-55.

22. Mease PJ, Genovese MC, Greenwald MW, Ritchlin CT, Beaulieu AD, Deodhar A, et al. Brodalumab, an anti-IL17RA monoclonal antibody, in psoriatic arthritis. N Engl J Med 2014;370:2295-306.

23. Kirkham B, McInnes IB, Mease P, Kremer J, Kandala S, Pricop L, et al. THU0421 Secukinumab is effective in reducing dactylitis and enthesitis using multiple measures in patients with psoriatic arthritis: data from a phase 3 randomized, multicenter, double-blind, placebo-controlled study (Future 2). Ann Rheum Dis 2015;74 Suppl 2:351.

24. Mease P, Sieper J, Van den Bosch F, Rahman P, Karunaratne PM, Pangan AL. Randomized controlled trial of adalimumab in patients with nonpsoriatic peripheral spondyloarthritis. Arthritis Rheumatol 2015;67:914-23.

25. Cohen J. Statistical power analysis for the behavioral sciences, 2nd ed. Hillsdale: Lawrence Erlbaum Associates; 1988.

26. Lukas C, Landewé R, Sieper J, Dougados M, Davis J, Braun J, et al; Assessment of SpondyloArthritis international Society. Development of an ASAS-endorsed disease activity score (ASDAS) in patients with ankylosing spondylitis. Ann Rheum Dis 2009;68:18-24

27. Poggenborg RP, Eshed I, Østergaard M, Sørensen IJ, Møller JM, Madsen OR, et al. Enthesitis in patients with psoriatic arthritis, axial spondyloarthritis and healthy subjects assessed by 'head-to-toe' whole-body MRI and clinical examination. Ann Rheum Dis 2015;74:823-9.

28. Gladman DD, Inman RD, Cook RJ, Maksymowych WP, Braun J, Davis JC, et al. International spondyloarthritis interobserver reliability exercise - the INSPIRE study: II. Assessment of peripheral joints, enthesitis, and dactylitis. J Rheumatol 2007;34:1740-5.

29. Mandl P, Niedermayer DS, Balint PV. Ultrasound for enthesitis: handle with care! Ann Rheum Dis 2012;71:477-9.

30. Terslev L, Naredo E, Iagnocco A, Balint PV, Wakefield RJ, Aegerter $\mathrm{P}$, et al; Outcome Measures in Rheumatology Ultrasound Task Force. Defining enthesitis in spondyloarthritis by ultrasound: results of a Delphi process and of a reliability reading exercise. Arthritis Care Res 2014;66:741-8.

31. Sakellariou G, Iagnocco A, Delle Sedie A, Riente L, Filippucci E, Montecucco C. Ultrasonographic evaluation of entheses in patients with spondyloarthritis: a systematic literature review. Clin Exp Rheumatol 2014;32:969-78.

32. Weber U, Lambert RG, Rufibach K, Maksymowych WP, Hodler J, Zejden A, et al. Anterior chest wall inflammation by whole-body magnetic resonance imaging in patients with spondyloarthritis: lack of association between clinical and imaging findings in a cross-sectional study. Arthritis Res Ther 2012;14:R3.

33. Aydin SZ, Tan AL, Hodsgon R, Grainger A, Emery P, Wakefield RJ, et al. Comparison of ultrasonography and magnetic resonance imaging for the assessment of clinically defined knee enthesitis in spondyloarthritis. Clin Exp Rheumatol 2013;31:933-6.

34. Song IH, Hermann K, Haibel H, Althoff CE, Listing J, Burmester G, et al. Effects of etanercept versus sulfasalazine in early axial spondyloarthritis on active inflammatory lesions as detected by whole-body MRI (ESTHER): a 48-week randomised controlled trial. Ann Rheum Dis 2011;70:590-6.

35. Feydy A, Lavie-Brion MC, Gossec L, Lavie F, Guerini H, Nguyen $\mathrm{C}$, et al. Comparative study of MRI and power Doppler ultrasonography of the heel in patients with spondyloarthritis with and without heel pain and in controls. Ann Rheum Dis 2012; 71:498-503. 